\title{
Pinless friction stir spot welding of aluminium alloy with copper interlayer
}

https://doi.org/10.1515/eng-2020-0090

Received Apr 08, 2020; accepted Aug 04, 2020

\begin{abstract}
Spot welding joints of Al-Mg-Si alloy (AA 6061-T6) were produced with and without the addition of copper interlayer using pinless friction stir spot welding (P-FSSW). To investigate the effects of welding parameters on the metallurgical and mechanical properties of the weldment, various tool plunge depth and dwell time were used. Optical microscopy, scanning electron microscopy, and energydispersive X-ray spectroscopy (EDS) have been used for microstructural characterisation. Meanwhile, the mechanical characterisation of the welded joints was evaluated by tensile-shear test. The experimental results showed that a larger bonding area and sound joint were achieved with the addition of $\mathrm{Cu}$ interlayer due to the improvement in thermal distribution. Also, an alloying reaction took place between the aluminium substrate and $\mathrm{Cu}$ interlayer during P-FSSW, forming intermetallic compounds layer in the interface through the diffusion process. The increasing of dwell time and plunge depth to some extent were beneficial to the formation of the joint and diffusion process, and thus increasing the tensile-shear load of the joints. The observed fracture mode of the joint was either completely shear off in the interface or complete nugget pullout.
\end{abstract}

Keywords: Pinless friction stir spot welding; $\mathrm{Cu}$ interlayer; Welding parameters; Microstructure; Tensile-shear

\section{Introduction}

The problem of the global environment and resources in recent years is tending to be more serious; thus, the attention on the reduction of environmental emissions and weight

\footnotetext{
${ }^{\star}$ Corresponding Author: Omar S. Salih: Department of Mechanical Engineering, Engineering Technical College-Baghdad, Middle Technical University, Baghdad, Iraq;

Email omar.s.salih@mtu.edu.iq

Balsam H. Abed, Khalid M. Sowoud: Department of Mechanical Power Engineering, Engineering Technical College-Baghdad, Middle Technical University, Baghdad, Iraq
}

structures is increasing, particularly in the aerospace and automotive industries. Also, the reduction of weight is a critical challenge in these industries to improve fuel economy, payload capability and enhancing the performance of the vehicle. In order to achieve these objectives, the using of lightweight materials such as magnesium, aluminium and aluminium matrix composite instead of steel alloys have been considered the most effective strategy to reduce vehicle mass [1-3]. Among these materials, aluminium alloys are considered a promising structural material due to high specific stiffness and strength to weight ratio combined with excellent corrosion resistance and high recycle [4, 5]. Many applications require joining thin aluminium sheets for structural components. However, the using of conventional resistance spot welding and riveting are no longer competitive to fulfil the service requirements in term of high reliability and efficiency. Because these techniques are combined by many disadvantages such as voids formation, large deformation, high energy consumption and gain extra weight from rivet material $[6,7]$. Thus, to benefit from increased utilisation of aluminium alloys and obtain high weld quality, there is a significant need to substitute the traditional joining methods by new joining technology like pinless friction stir spot welding (P-FSSW) $[8,9]$.

P-FSSW is a solid-state joining process derivative from linear friction stir welding (FSW) process in which plate welded by plastic flowing at elevated temperature. In PFSSW, a non-consumable rotating tool consisting of shoulder only is plunged into overlapped metal sheets for specific depth then held for a short time referred to as dwell period without the translation of welding tool afterwards retracting the tool, as illustrated in Figure 1. When the rotating tool interacts with the upper sheet and then plunged, heat is generated due to the material plastic deformation and localised friction action. The generated heat soften the material in the nugget zone and form a joint by the vertical plastic flow between lower and upper sheets [10-13].

As a solid-state joining method, P-FSSW is considered more energy-efficient and friendly to the environment due to the short welding cycle and low heat input. The generated temperature during the welding process is lower than

๑ Open Access. (C 2020 B. H. Abed et al., published by De Gruyter. (cc) BY 4.0 License

This work is licensed under the Creative Commons Attribution 

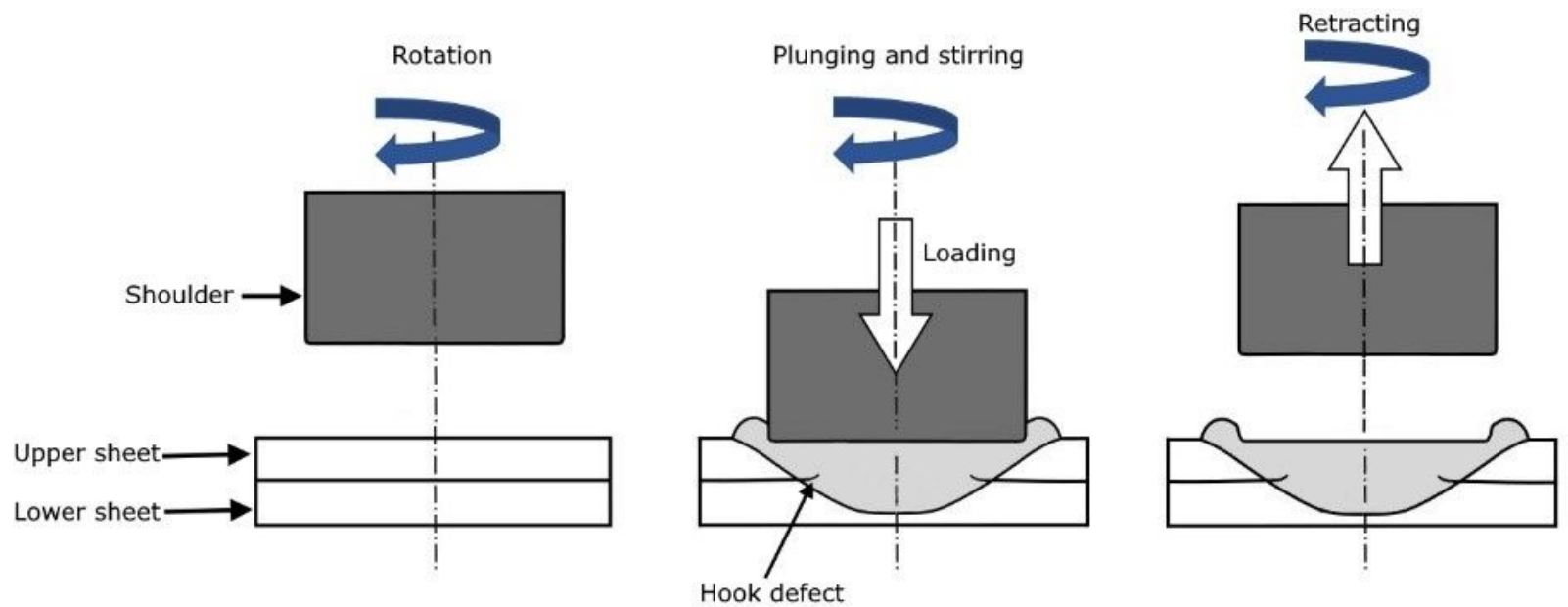

Figure 1: Schematic illustration of pinless friction stir spot welding

the melting point of base materials; thus, the P-FSSW joint is free from defects that commonly associated with conventional welding process $[14,15]$. Furthermore, the two inevitable defects (weld keyhole and hook defect) which formed in the joint welded by traditional friction stir spot welding (FSSW) are significantly reduced when using PFSSW. The weld keyhole is resulted from plunging force and squeezing the softened material to the upper sheet and leave a round indentation in the weld after tool retraction. This defect leads to excessive thinning of the top sheet in the nugget zone and lowering the strength of joints. Meanwhile, the hook defect (see Figure 1) is happened due to upward plastic flow of softened metal from the bottom to upper sheet and lead to a reduction in the bearing area outside the nugget zone. Thus, it is considered as mechanical discontinuity within the top sheet cause stress concentration at hook tip.

Tool shoulder design is critical to the success of PFSSW technology, as this factor significantly affect heat generation and material flow [16]. Tozaki et al. [17] developed a P-FSSW tool with a shoulder surface contains scroll groove feature. The performance of the tool has been investigated by joining AA6061-T4 alloy under various welding parameters. They reported that the developed tool had superior performance and maximised the tensile lap shear strength of the weldments as compared to the conventional tool with a pin due to the elimination of the keyhole and reducing hook effect. Also, with the profiled tool, the material flow enhanced due to the increase of the contact area with the sheet surface, which is led to increasing the depth of deformation zone penetration and assisting weld formation. The effect of shoulder end surface geometry on the improvement of the weld quality of P-FSSW joint was also confirmed by Bakavos's et al. [18] work.
Besides the effect of tool design on the controlling the properties of P-FSSW joint, welding parameters such as dwell time, shoulder plunge depth and tool rotation speed also play a significant role in determining the strength of joint [19]. Li et al. [20] investigated the effect of rotating speed and dwell time on lap shear strength of AA 2198T8 joints produced by P-FSSW. The results of this work indicated that tensile-shear force increased with rotation speed and duration time due to the increase of heat input and material flow. However, with dwell time more than 9 $\mathrm{s}$, the hook defect extends clearly to the top sheet surface and lowering the effective thickness and joint strength.

Zhikang et al. [21] emphasized that a critical shoulder penetration in P-FSSW process is essential to get reliable weld performance, which is confirmed by the results of the work that has been done by Aota and Ikeuchi [22]. They pointed out that the low carbon steel plates with $0.5 \mathrm{~mm}$ thick cannot be welded when using tool plunge depths of $0.05 \mathrm{~mm}$ or less. As the plunge depth increases the bonded region size and failure load increased. However, the excessive penetration result in thickness reduction of the upper sheet and hooking went up, which reduced the quality of joints. This behaviour is also reported by Xu et al. [23].

Recently, a new novel process named friction stir brazing (FSB) was developed to improve the quality of weldment by the formation of a metallurgical bond beside the plastic flow [24, 25]. Xu et al. [26] studied the influence of adding $\mathrm{Zn}$ interlayer having different thicknesses on the joint strength of AZ31 Mg alloy produced by the conventional tool with various shoulder end surface and diameter. The obtained results showed an improvement is the strength of the joint welded with a suitable thickness interlayer in comparison to that obtained without interlayer. They claim this performance to the formation of a 
Table 1: Chemical composition (wt.\%) of AA 6061-T6 aluminium alloy

\begin{tabular}{ccccccccc}
\hline $\mathrm{Si}$ & $\mathrm{Fe}$ & $\mathrm{Cu}$ & $\mathrm{Mn}$ & $\mathrm{Mg}$ & $\mathrm{Cr}$ & $\mathrm{Zn}$ & $\mathrm{Ti}$ & $\mathrm{Al}$ \\
\hline 0.8 & 0.68 & 0.227 & 0.134 & 1.16 & 0.347 & 0.059 & 0.056 & Bal. \\
\hline
\end{tabular}

Table 2: Mechanical properties of AA 6061-T6 aluminium alloy

\begin{tabular}{ccc}
\hline $\begin{array}{c}\text { Tensile stress } \\
(\mathrm{MPa})\end{array}$ & $\begin{array}{c}\text { Yield stress } \\
(\mathrm{MPa})\end{array}$ & Elongation (\%) \\
\hline 348 & 254 & 11.5 \\
\hline
\end{tabular}

brazed zone, which is substitute the unbonded area in the joints produced without using interlayer and elimination the hook defects as well. Later, Xu et al. [23] examined the effect of using P-FSSW tool with different end surface geometry (convex, concave and flat) and tool plunge depth on the joints properties of Mg-3Al-1Zn alloy welded with and without using $\mathrm{Zn}$ interlayer. They reported that the using of the concave tool end lead to an increase in the joint strength of weldment in comparison to the joint produced by conventional tool due to the elimination of hook defect and weld keyhole. Also, the fracture load increased by increasing the plunge depth due to increasing the contact area underneath the shoulder and thereby increasing the discontinuous reaction layer.

In view of the aforementioned, the effect of welding parameters and using interlayer on the metallurgical and mechanical characterisations of the welded joint are still needed more clarification. Therefore, the current work aims to study the feasibility of using $\mathrm{Cu}$ interlayer and PFSSW tool to eliminate the weld keyhole and hook defects and improve the weld quality of 6061-T6 joints assisted by metallurgical reaction beside material plastic flow. Particular emphasis has been given to clarify the effects of welding time and plunge depth on the microstructural evolution and joint performance.

\section{Experimental work}

In the current study, rolled sheets AA 6061-T6 with a thickness of $1.5 \mathrm{~mm}$ is used as a substrate material. Table 1 and Table 2 listed their chemical composition and mechanical properties, respectively. Also, a thin sheet of commercially pure copper of around $100 \mu \mathrm{m}$ thickness was chosen as an interlayer between the faying surface of aluminium alloy.

The lap-shear tensile specimens were made based on American Welding Society standard (AWS C1.1M/C1.1:2012), two sheets having width and length of 25

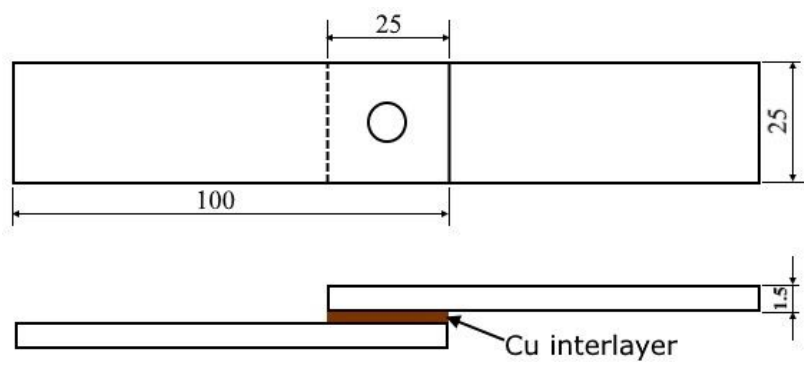

Figure 2: Schematic illustration of the tensile-shear specimen and the position of $\mathrm{Cu}$ interlayer (all dimensions in millimetre)

and $100 \mathrm{~mm}$, respectively with an overlap area of $25 \mathrm{~mm}$ $\times 25 \mathrm{~mm}$ were welded, as shown in Figure 2. For all joints, the P-FSSW has been done in the centre of the overlap area by using universal vertical milling machine. A pinless tool with $10 \mathrm{~mm}$ shoulder diameter and tapered edge by $45^{\circ}$ made from tungsten carbide was used in the welding process to avoid the formation of weld keyhole. Before the welding process, the substrate and interlayer metal were cleaned with alcohol to remove the impurities such as oil and dirt. The welding process has been conducted at various tool plunge depth and dwells time, which were $0.1,0.2$ and $0.3 \mathrm{~mm}$, and 10, 15 and $20 \mathrm{~s}$, respectively. The tool plunge rate and rotation speed were kept constant at $16 \mathrm{~mm} / \mathrm{min}$ and $1800 \mathrm{rpm}$, respectively. The specimens were welded in an overlapped configuration without and with using interlayer metal. So, in total, eighteen joints denoted as W1-W18 were produced, as shown in Table 3. For comparison hereinafter, the welded samples were classified into two groups based on using interlayer: without interlayer (W1-W9) and with interlayer (W10-W18).

As the research goal of this work is to study the feasibility of using P-FSSW with $\mathrm{Cu}$ interlayer and the contribution of process parameters on the quality of weldment, metallurgical and mechanical characterisation of P-FSSW joints were investigated. For macro- and microstructure observation, the P-FSSW joints were cross-sectioned through the centre of joints and then prepared by mechanical grinding with 220-4000 grit silicon carbide abrasive papers followed by polishing with 1 and $0.5 \mu \mathrm{m}$ alumina. To reveal the macrostructural characteristics of the welding zone, acid etching was carried out with Poulton's reagent. The microstructures were examined by an optical microscope 
Table 3: Welding parameters of the P-FSSW

\begin{tabular}{|c|c|c|c|c|}
\hline Sample No. & Rotation speed (rpm) & Dwell time (s) & Plunge depth (mm) & Cu interlayer \\
\hline W1 & \multirow{18}{*}{1800} & & 0.1 & \multirow{9}{*}{ Without } \\
\hline W2 & & 10 & 0.2 & \\
\hline W3 & & & 0.3 & \\
\hline W4 & & & 0.1 & \\
\hline W5 & & 15 & 0.2 & \\
\hline W6 & & & 0.3 & \\
\hline W7 & & \multirow{3}{*}{20} & 0.1 & \\
\hline W8 & & & 0.2 & \\
\hline W9 & & & 0.3 & \\
\hline W10 & & \multirow{3}{*}{10} & 0.1 & \multirow{9}{*}{ With } \\
\hline W11 & & & 0.2 & \\
\hline W12 & & & 0.3 & \\
\hline W13 & & \multirow{3}{*}{15} & 0.1 & \\
\hline W14 & & & 0.2 & \\
\hline W15 & & & 0.3 & \\
\hline W16 & & \multirow{3}{*}{20} & 0.1 & \\
\hline W17 & & & 0.2 & \\
\hline W18 & & & 0.3 & \\
\hline
\end{tabular}

and scanning electron microscope (SEM, Inspect S50) with energy-dispersive X-ray spectroscopy (EDS) capabilities.

The tensile-shear test was performed at ambient temperature using a Zwick machine with a constant crosshead speed rate of $10 \mathrm{~mm} / \mathrm{min}$. During testing, two shims were employed in the test assembly to minimize the effect of bending moment. Three tensile -shear samples tested for each welding condition, and the average of the results was presented for discussion.

\section{Results and discussion}

\subsection{Macromorphology and microstructure}

Figure 3 shows the microstructure of the as-received parent metal AA 6061-T6. It can be seen that the grain structure consists of a highly elongated pancake shape grain with an average length of about $300 \mu \mathrm{m}$. This structure has typically resulted from the rolling process.

Figure 4 shows the cross-section macrostructure and microstructure of a typical joint welded without $\mathrm{Cu}$ interlayer W7. Regardless of welding parameters, the macrostructure of joint (Figure 4 (a)) reveals that the friction stir zone (FSZ) consists of two regions, namely; the stirring zone (SZ), which is the area highlighted by the red dashed lines adjacent by the thermomechanically affected zone (TMAZ). Also, it is showing the formation of

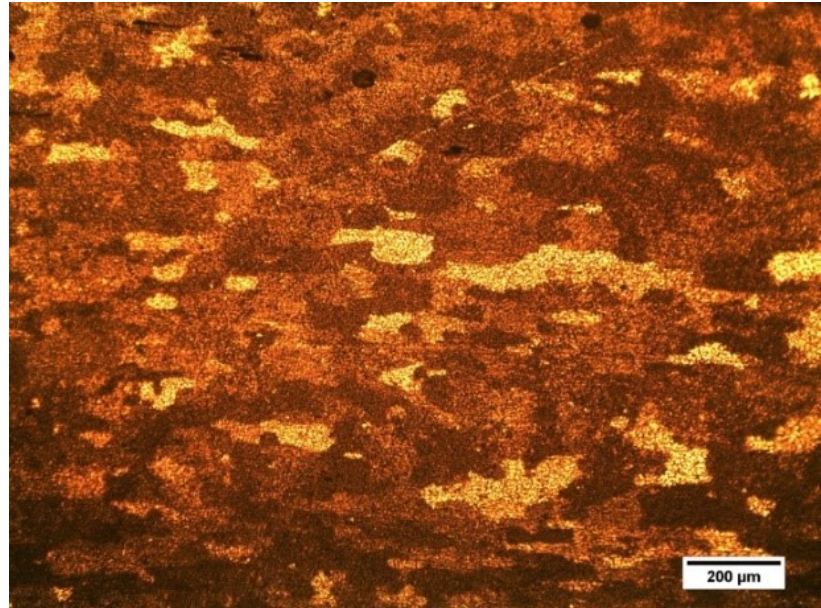

Figure 3: Microstructure of substrate metal AA 6061-T6

a mechanically mixed zone between the upper and lower sheets interface, and it has a curved line sunk-down profile due to the plunging force. The size of the mixed zone and curvature profile increased by increasing the dwell time and plunge depth. However, at the weld centre, there is no excessive penetration depth from the top sheet into the bottom layer, and this led to avoid the formation of hook defect. Similar behaviour has been reported by Bakavos et al. [18], and they related this to the design of the tool (pinless and shoulder featureless). Figure 4 (b) shows a higher magnification of the transition zone (TZ) from the 

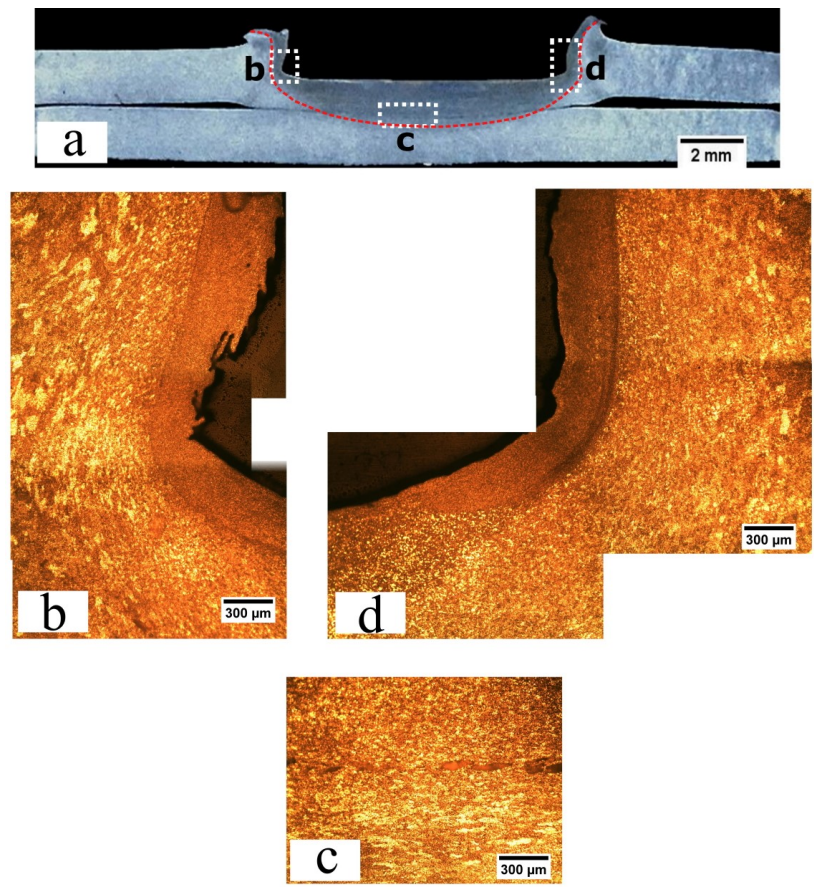

Figure 4: Metallurgical characterisation of weld cross-section without Cu interlayer (W7 P-FSSW joint): (a) macrostructure of joints, (b) transition zone in the AS, (c) interface in the centre of joint and (d) transition zone in the RS

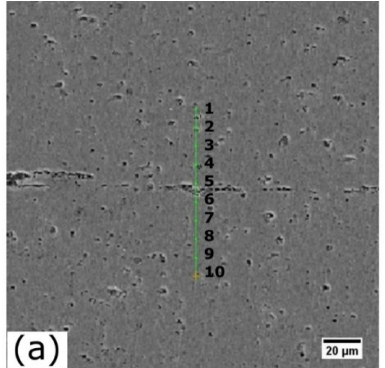

Figure 5: Microstructure in the interface of W7 P-FSSW joint (a) SEM image and (b) EDX map

base metal (BM) to the $\mathrm{SZ}$ on the advanced side (AS). The material in $\mathrm{TZ}$ undergoes thermal cycling and mechanical stirring, and it consists of sharply rotated elongated grains around the nugget zone in an upward flowing pattern, partially recrystallised heavily deformed grains in the TMAZ and completely recrystallised with fine equiaxed grains in the SZ. On the other hand, the microstructure of TZ in the retreating side (RS) (Figure 4 (d)) shows less rotation in the elongated grains of the BM with more diffused in the interface with TMAZ, which is related to the flow mechanism of soft metal during welding process [27].

Figure 4 (c) and Figure 5 show the magnified images and SEM micrographs with EDX map in the centre of the joint. The related EDS spot analysis result of the interface is
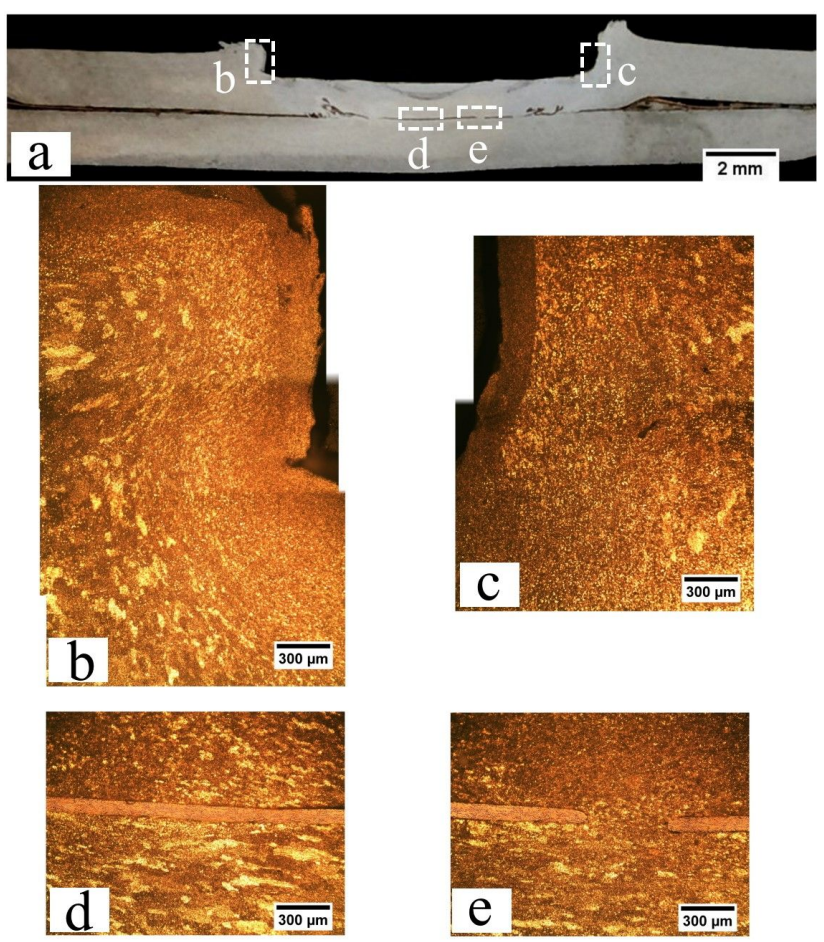

Figure 6: Metallurgical characterisation of weld cross-section with Cu interlayer (W15 P-FSSW joint): (a) macrostructure of joints, (b) transition zone in the AS, (c) transition zone in the RS and (d, e) interface in the centre of joint

presented in Table 4. In comparison to the structure of the $\mathrm{BM}$, finer grains were formed in this region indicating the occurrence of dynamic recrystallization during the welding process, which is resulted from high-temperature exposure and intense plastic deformation within the SZ. The grain refinement increases when moving closer to the tool end due to the excessive plastic deformation effects, which farther contribute to the recrystallization process. Also, it is evident that the interface in the centre of FSZ is rough and heterogeneous and there is partial bonding between the upper and lower sheet (metallurgical defect), which can be related to the insufficient stirring time and heat generation.

Figure 6 shows the cross-section macrograph and the related magnified microstructures of regions b-e of a typical P-FSSW joint welded with $\mathrm{Cu}$ interlayer W15. As with weldment without an interlayer, the macrostructure profile reveals two distinct regions in the TZ (Figure 6 (a)): the SZ and the TMAZ without formation geometric defect (hook defect) in both AS and RS, as illustrated in Figure 6 (b) and (c), respectively. However, it can be seen that the metallurgical defect in term of partial bonding in the interface has not found and continuous bound was obtained (see Figure 6 (d and e)). 
Table 4: Chemical spot analysis result at the interface of W7 P-FSSW joints

\begin{tabular}{cccccccc}
\hline Point & \multicolumn{9}{c}{ Element (wt\%) } & \multirow{2}{*}{ Region } \\
\cline { 2 - 6 } & $\mathrm{Al}$ & $\mathrm{Mg}$ & $\mathrm{Si}$ & $\mathrm{Cu}$ & 0 & Other & \\
\hline 1 & 86.94 & 2.26 & 1.03 & 0.66 & 0.89 & 8.22 & Al substrate \\
2 & 89.2 & 1.53 & 0.95 & 0.72 & 1.09 & 6.51 & Al substrate \\
3 & 90.7 & 1.55 & 1.1 & 0.71 & 1.08 & 4.86 & Al substrate \\
4 & 89.84 & 1.87 & 1.06 & 0.73 & 1.42 & 5.08 & Welding interface \\
5 & 89.83 & 1.33 & 0.82 & 0.7 & 1.04 & 6.28 & Welding interface \\
6 & 88.48 & 1.34 & 0.9 & 0.65 & 1.18 & 7.45 & Welding interface \\
7 & 90 & 1.46 & 0.91 & 0.63 & 1.03 & 5.97 & Welding interface \\
8 & 89.28 & 1.49 & 0.84 & 0.68 & 1.32 & 6.39 & Al substrate \\
9 & 89.43 & 1.42 & 1.02 & 0.64 & 1.05 & 6.44 & Al substrate \\
10 & 90.35 & 1.56 & 1.03 & 0.67 & 2.01 & 4.38 & Al substrate \\
\hline
\end{tabular}

Table 5: Chemical spot analysis result at the interface of W15 P-FSSW joints

\begin{tabular}{cccccccl}
\hline Point & \multicolumn{9}{c}{ Element $(w t \%)$} & \multicolumn{2}{l}{ Region } \\
\cline { 2 - 6 } & $\mathrm{Al}$ & $\mathrm{Mg}$ & $\mathrm{Si}$ & $\mathrm{Cu}$ & 0 & Other & \\
\hline 1 & 94.76 & 1.38 & 1.03 & 0.73 & 1.52 & 0.58 & Al substrate \\
2 & 84.11 & 4.82 & 1.85 & 0.73 & 1.71 & 6.78 & Al substrate \\
3 & 37.78 & 3.11 & 3.5 & 28.29 & 23.09 & 4.23 & Al-Cu transition zone \\
4 & 4.56 & 4.11 & 2.75 & 83.46 & 4.03 & 1.09 & Cu layer \\
5 & 3.62 & 3.67 & 3.32 & 85.11 & 3.38 & 0.9 & Cu layer \\
6 & 4.77 & 5.26 & 3.52 & 76.98 & 8.37 & 1.1 & Cu layer \\
7 & 80.2 & 0.46 & 12.9 & 0.38 & 5.6 & 0.46 & Al-Cu transition zone \\
8 & 79.5 & 2.39 & 4.91 & 1.12 & 9.72 & 2.36 & Al-Cu transition zone \\
9 & 90.79 & 1.42 & 1.05 & 0.62 & 1.19 & 4.93 & Al substrate \\
10 & 94.88 & 1.24 & 0.96 & 0.62 & 1.64 & 0.66 & Al substrate \\
\hline
\end{tabular}
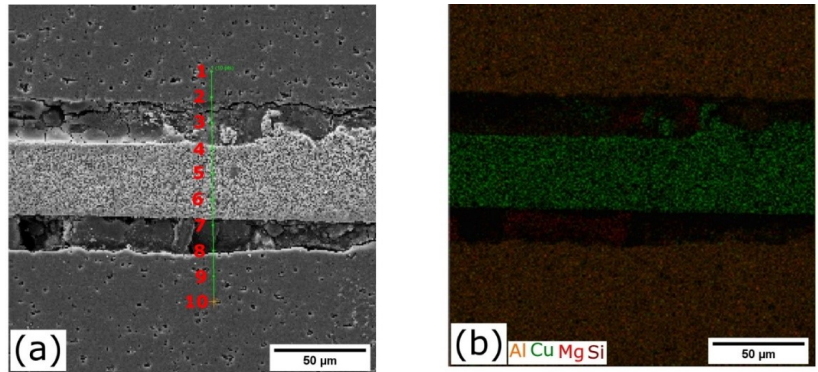

Figure 7: Microstructure in the interface of W15 P-FSSW joints (a) SEM image and (b) EDX map

Figure 7 shows a typical SEM photograph with EDX map of the interface in the centre of W15 P-FSSW joint. It was found that there is a metallurgical reaction in the interface between $\mathrm{Al}$ substrate and $\mathrm{Cu}$ interlayer, as shown in Figure 7 ( $a$ and $b)$. The interface and reaction layer in Figure 7 (a) were farther investigated and analysed quantitatively and presented in Table 5 . The spots analysis results and chemical composition of Al substrate (points 1, 2,
9 and 10), $\mathrm{Al}-\mathrm{Cu}$ transition zone (points 3, 7 and 8 ) and $\mathrm{Cu}$ interlayer (points 4, 5 and 6), are suggesting that $\mathrm{Al}$ and $\mathrm{Cu}$ elements diffused into each other. These elements do not have complete solubility in the solid-state; instead, they formed an intermetallic compound (IMC) in the reaction layer. Based on these results, it thought that a diffusion bond between aluminium and copper was formed in the transition zone beside the plastic flow. The mechanism of formation diffusion bound between metallurgically incompatible metals such as $\mathrm{Al}$ and $\mathrm{Cu}$ could be explained based on Calvo et al. [28] work. They stated that the formation of the diffusion bonding happened under high pressure and temperature, and it consists of three stages, namely; contact stage, interface diffusion stage (IMC formation) and growth of the IMC. Due to applied pressure in the first stage, plastic deformation occurs in the contact interface and leads to an increase in the contact area between the faying surfaces. Yield deformation mechanism and oxide film fracture mechanism were dominating in this stage. By increasing the temperature in the second stage, diffusive 
flows of element starting through the bonding interface and forms IMC. Meanwhile, the growth of the IMC happened in the third stage. Based on this explanation and the mechanism of joint formation during P-FSSW under high pressure, plastic deformation and temperature, it could be concluded that the joint produced with $\mathrm{Cu}$ interlayer is formed by plastic flow and diffusion bonding.

\subsection{Influence of FSSW parameters on tensile-shear}

Figure 8 shows the influence of dwell time on the tensileshear load under different plunge depth for the joints welded without $\mathrm{Cu}$ interlayer (W1-W9). The lowest fracture load is achieved for the joints welded at $10 \mathrm{~s}$ dwell time and plunge depth of $0.2 \mathrm{~mm}$ (W2). As the dwell time and plunge depth increase to some extent, the tensile-shear separation load increased, and the maximum obtained value was $3.22 \mathrm{kN}$ at $15 \mathrm{~s}$ and $0.1 \mathrm{~mm}$ (W4). Higher dwell time provides sufficient time to form $\mathrm{SZ}$ and results in a stronger joint. The farther increasing of plunge depth to $0.3 \mathrm{~mm}$ combined by longest dwell time $20 \mathrm{~s}$ (W9) led to a reduction in the effective thickness of the upper plate and then lowering the fracture load. Similar behaviour has also been reported by Li et al. [20]. The variation in the fracture load with welding parameters can be related to the frictional heat, material flow and bond size as well as hooking features [29]. Also, Yin et al. [30] confirmed that the bonding width and hook defects determine the strength of welded joints.

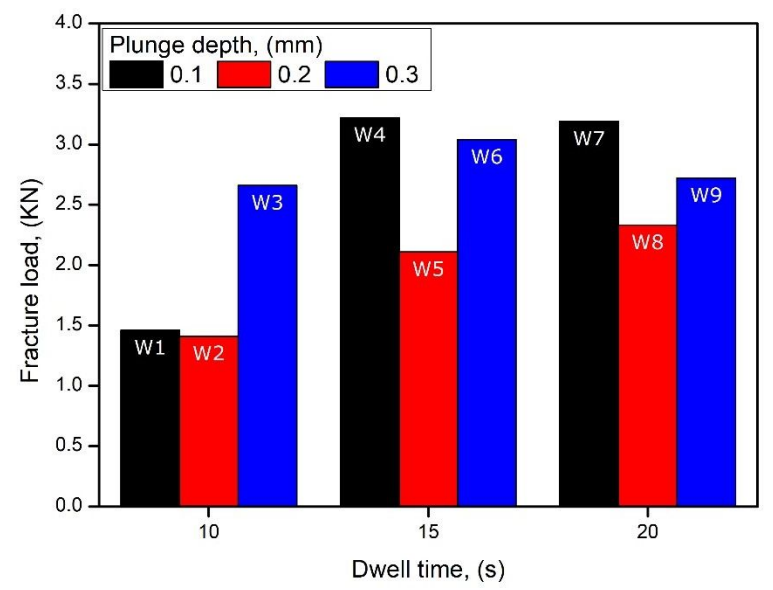

Figure 8: Tensile-shear load as a function of dwell time under different plunge depth for P-FSSW joints welded without $\mathrm{Cu}$ interlayer
Figure 9 shows the tensile-shear fracture load of the joints welded with $\mathrm{Cu}$ interlayer (W10-W18) under different welding conditions. It is evident that there is a good improvement in the mechanical behaviour of the welded joints as compared with joints welded under the same welding conditions without $\mathrm{Cu}$ interlayer. This can be related to the formation of a homogenous joint with less voids in the joint interface, as presented in the previous section (3.1). However, there is a reduction in the strength of P-FSSW joint when the dwell time increases to $20 \mathrm{~s}$, which could be related to the IMC growth in the interface. Calvo et al. [28] pointed out that there is a positive correlation between the welding time and IMC size. Thus, it is thought that the higher amount of IMC leads to an increase in the brittleness of the P-FSSW joint.

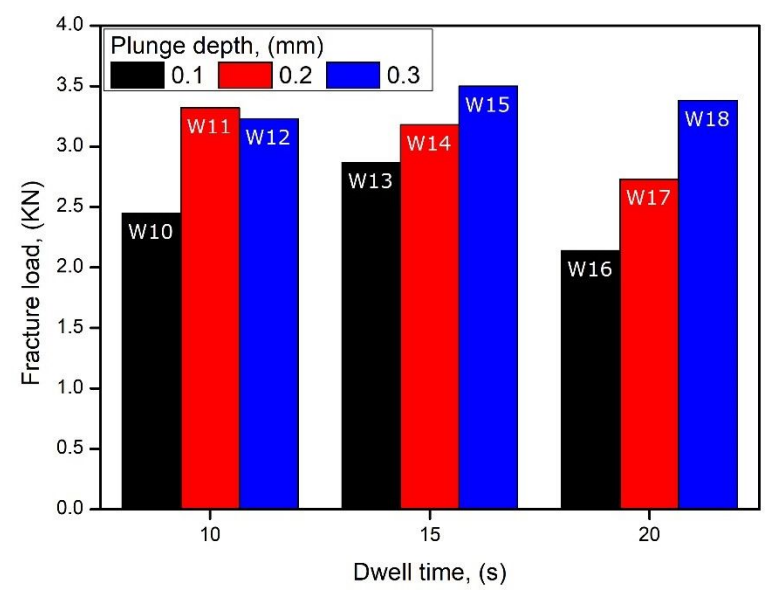

Figure 9: Tensile-shear load as a function of dwell time under different plunge depth for P-FSSW joints welded with $\mathrm{Cu}$ interlayer

\subsection{Fractographic morphologies and fracture mechanism}

To correlate the fracture mechanism with the tensile shear failure load presented in section 3.2, the fractographic morphologies of P-FSSW joints were examined and presented in Figure 10. According to the results, two distinctive fracture modes were observed. Firstly, shear off completely in the lap joint interface between the lower and upper sheets. This mode of fracture is dominated in most joints, which is in agreement with the work that has been done by Shin and Leon [31]. The mechanism of shear off fracture mode was explained by Wang et al. [32] and Chu et al. [33]. They stated that the expansion of the upper sheet at shoulder periphery constrained by surrounding materials, which are 


\begin{tabular}{|c|c|c|c|c|c|}
\hline \multirow[b]{2}{*}{ Sample } & \multicolumn{2}{|c|}{ Without Cu interlayer } & \multirow[b]{2}{*}{ Sample } & \multicolumn{2}{|c|}{ With $\mathrm{Cu}$ interlayer } \\
\hline & $\begin{array}{l}\text { Bottom of } \\
\text { upper sheet }\end{array}$ & $\begin{array}{c}\text { Top of lower } \\
\text { sheet }\end{array}$ & & $\begin{array}{c}\text { Bottom of } \\
\text { upper sheet }\end{array}$ & $\begin{array}{c}\text { Top of lower } \\
\text { sheet }\end{array}$ \\
\hline w1 & & & W10 & & \\
\hline W2 & & & W11 & & \\
\hline W3 & & & W12 & & \\
\hline W4 & & & W13 & & \\
\hline W5 & & & W14 & & \\
\hline W6 & & & W15 & & \\
\hline W7 & & & w16 & & \\
\hline W8 & & & W17 & & \\
\hline W9 & & & W18 & & \\
\hline
\end{tabular}

Figure 10: Fractographic views of tensile-shear P-FSSW joint

leading to bending the upper sheet and form a slight gap between the two sheets. When the hook angle is obtuse, the crack initiated at the end of gap and extended along the bottom of nugget then fractured. Secondly, the circumferential or the complete nugget pullout failure mode has occurred in W11 P-FSSW joint. It can be clearly seen that the failure happens near to the outer perimeter of the shoulder indentation, and the nugget pulled out and stayed in the lower sheet. The mechanism of this failure can be related to the changing of hook angle form obtuse to acute, which is lead to the extension of crack from hook defect to the upper surface [33].
Furthermore, there was no actual nugget (less mixing in the interface between the lower and upper plate) developed at the stirring zone in the joints welded without $\mathrm{Cu}$ layer and in particular weldment produced with 0.1 and 0.2 $\mathrm{mm}$ plunge depth and lower dwell time of $10 \mathrm{~s}$ (W1 and W2), and also for joint welded at $0.1 \mathrm{~mm}$ plunge depth and 15 s dwell time (W4). This can be related to insufficient heat input, stirring time and surface oxidisation. On the other hand, it is evident that the adding of $\mathrm{Cu}$ interlayer leads to an increase in the welded area as compared to the joint welded under the same welding conditions (see Figure 10). Thus, it can be concluded that the flowability of softened 
metal and heat distribution between the top and bottom sheet is improved by adding $\mathrm{Cu}$ layer.

\section{Conclusions}

In this work, P-FSSW of aluminium alloy AA 6061-T6 was realised with and without adding $\mathrm{Cu}$ interlayer. The effect of tool plunge depth and dwell time on metallurgical and mechanical characterisation of the welded joints were investigated. The results indicate that there is a partial joint formation in the interface of joints welded without $\mathrm{Cu}$ interlayer resulted from insufficient mixing and aluminium oxide layer on the substrate. The addition of $\mathrm{Cu}$ interlayer leads to improve the joint formation and form a more homogenous and continuous interface. This improvement in joint continuity could be related to the increases in the bonding area and form intermetallic compounds resulting from the reaction between the substrate metal and interlayer. The obtained results also indicate that the tool plunge depth and welding time profoundly influenced the strength of joints. Higher fracture load was achieved for the joints produced with $\mathrm{Cu}$ interlayer than that welded without $\mathrm{Cu}$. Two different fracture modes were detected for welded joints, completely shear off in the interface and complete nugget pullout.

Acknowledgement: The authors would like to thank the University of Technology and the Institute of TechnologyBaghdad for providing access to instrumentation and technical assistance

\section{References}

[1] Zhang Z, Yang X, Zhang J, Zhou G, Xu X, Zou B. Effect of welding parameters on microstructure and mechanical properties of friction stir spot welded 5052 aluminum alloy. Mater Des. 2011;32(89):4461-70.

[2] Salih OS, Ou H, Wei X, Sun W. Microstructure and mechanical properties of friction stir welded AA6092/SiC metal matrix composite. Mater Sci Eng A. 2019;742:78-88.

[3] Badarinarayan H, Yang Q, Zhu S. Effect of tool geometry on static strength of friction stir spot-welded aluminum alloy. Int J Mach Tools Manuf. 2009;49(2):142-8.

[4] Wang G, Zhao Y, Hao Y. Friction stir welding of high-strength aerospace aluminum alloy and application in rocket tank manufacturing. J Mater Sci Technol. 2018;34(1):73-91.

[5] Salih OS, Neate N, Ou H, Sun W. Influence of process parameters on the microstructural evolution and mechanical characterisations of friction stir welded Al-Mg-Si alloy. J Mater Process Technol. 2020;275:116366.
[6] Kubit A, Kluz R, Trzepieciński T, Wydrzyński D, Bochnowski W. Analysis of the mechanical properties and of micrographs of refill friction stir spot welded 7075-T6 aluminium sheets. Arch Civ Mech Eng. 2018;18(1):235-44.

[7] Liu Z, Cui H, Ji S, Xu M, Meng X. Improving joint features and mechanical properties of pinless fiction stir welding of alcald 2A12-T4 aluminum alloy. J Mater Sci Technol. 2016;32(12):1372-7.

[8] Uematsu Y, Tokaji K. Comparison of fatigue behaviour between resistance spot and friction stir spot welded aluminium alloy sheets. Sci Technol Weld Join. 2009;14(1):62-71.

[9] Fujimoto M, Inuzuka M, Koga S, Seta Y. Development of friction spot joining. Weld World. 2005;49(3-4):18-21.

[10] Yang Q, Mironov S, Sato Y, Okamoto K. Material flow during friction stir spot welding. Mater Sci Eng A. 2010;527(16-17):438998.

[11] Mubiayi MP, Akinlabi ET, editors. Friction stir spot welding of dissimilar materials-an overview. World Congress on Engineering and Computer Science 2014; San Francisco, USA.

[12] Yang Q, Mironov S, Sato Y, Okamoto K. Material flow during friction stir spot welding. Mater Sci Eng A. 2010;527(16-17):438998.

[13] Li W, Li J, Zhang Z, Gao D, Wang W, Dong C. Improving mechanical properties of pinless friction stir spot welded joints by eliminating hook defect. Mater Des. 2014;62:247-54.

[14] Hancock R. Friction welding of aluminum cuts energy costs by 99\%. Welding Journal-New York. 2004;83(2):40-3.

[15] Karthikeyan R, Balasubramanian V. Predictions of the optimized friction stir spot welding process parameters for joining AA2024 aluminum alloy using RSM. Int J Adv Manuf Technol. 2010;51(14):173-83.

[16] Tozaki Y, Uematsu Y, Tokaji K. Effect of tool geometry on microstructure and static strength in friction stir spot welded aluminium alloys. Int J Mach Tools Manuf. 2007;47(15):2230-6.

[17] Tozaki Y, Uematsu Y, Tokaji K. A newly developed tool without probe for friction stir spot welding and its performance. J Mater Process Technol. 2010;210(6-7):844-51.

[18] Bakavos D, Chen Y, Babout L, Prangnell P. Material interactions in a novel pinless tool approach to friction stir spot welding thin aluminum sheet. Metall Mater Trans, A Phys Metall Mater Sci. 2011;42(5):1266-82.

[19] Cox CD, Aguilar JR, Ballun MC, Strauss AM, Cook GE. The application of a pinless tool in friction stir spot welding: an experimental and numerical study. Proc Inst Mech Eng, D J Automob Eng. 2014;228(11):1359-70.

[20] Li W, Chu Q, Yang X, Shen J, Vairis A, Wang W. Microstructure and morphology evolution of probeless friction stir spot welded joints of aluminum alloy. J Mater Process Technol. 2018;252:6980.

[21] Shen Z, Ding Y, Gerlich AP. Advances in friction stir spot welding. Crit Rev Solid State Mater Sci. 2019:1-78.

[22] Aota K, Ikeuchi K. Development of friction stir spot welding using rotating tool without probe and its application to low-carbon steel plates. Welding International. 2009;23(8):572-80.

[23] Xu R, Ni D, Yang Q, Liu C, Ma Z. Pinless friction stir spot welding of Mg-3Al-1Zn alloy with Zn interlayer. J Mater Sci Technol. 2016;32(1):76-88.

[24] Zhang G, Su W, Zhang J, Wei Z. Friction stir brazing: a novel process for fabricating Al/steel layered composite and for dissimilar joining of Al to steel. Metall Mater Trans, A Phys Metall Mater Sci. 2011;42(9):2850-61. 
[25] Zhang G, Zhang K, Zhang L, Zhang J. Approach to disrupting thick intermetallic compound interfacial layer in friction stir brazing (FSB) of Al/Cu plates. Sci Technol Weld Join. 2014;19(7):554-9.

[26] Xu R, Ni D, Yang Q, Liu C, Ma Z. Influence of Zn interlayer addition on microstructure and mechanical properties of friction stir welded AZ31 Mg alloy. J Mater Sci. 2015;50(12):4160-73.

[27] Mishra RS, Ma ZY. Friction stir welding and processing. Mater Sci Eng Rep. 2005;50(1-2):1-78.

[28] Calvo F, Ureng A, De Salazar JG, Molleda F. Special features of the formation of the diffusion bonded joints between copper and aluminium. J Mater Sci. 1988;23(6):2273-80.

[29] Su P, Gerlich A, North T. Friction stir spot welding of aluminum and magnesium alloy sheets. SAE Technical Paper; 2005. Report No.: 0148-7191. https://doi.org/10.4271/2005-01-1255.
[30] Yin Y, Sun N, North T, Hu S. Influence of tool design on mechanical properties of AZ31 friction stir spot welds. Sci Technol Weld Join. 2010;15(1):81-6.

[31] Shin HS, de Leon M. Weldability assessment of friction stir spot welded lightweight alloys using pin and pinless tools. Sci Technol Weld Join. 2016;21(2):99-105.

[32] Wang DA, Chao CW, Lin PC, Uan JY. Mechanical characterization of friction stir spot microwelds. J Mater Process Technol. 2010;210(14):1942-8.

[33] Chu Q, Yang X, Li W, Li Y. Microstructure and mechanical behaviour of pinless friction stir spot welded AA2198 joints. Sci Technol Weld Join. 2016;21(3):164-70. 